\title{
АВТОМАТИЗАЦІЯ ПРОЦЕСІВ ЦИФРОВОГО ВИЗНАЧЕННЯ ТЕХНОЛОГІЧНИХ ПАРАМЕТРІВ ПОВІТРЯНО-ВАКУУМНОЇ СИСТЕМИ ПОДАЧІ АРКУШІВ
}

๑ В. Ф. Морфлюк д.Т.н., професор, І. С. Карпенко, аспірантка, нТУУ «КПІ», Київ, Україна

Разработана система цифрового измерения и стабилизации технологических параметров воздушно-вакуумной системы подачи листов. Проведены экспериментальные исследования процессов статистического определения давления воздуха в раздувах листопитающей системы, которые обеспечивают надежность подачи листа на основе цифровых средств измерения и обработки с использованием проблемно-ориентированных программных средств.

The system of digital measurement and stabilization of technological parameters of sheets feeder by the air-vacuum system is developed. The experimental research of processes of the air pressure statistical determination into the blower of the paper feed system that ensure reliability of the sheets feed based on digital measurement and processing with the use of the problemoriented software is realized.

\section{Постановка проблеми}

Продуктивність папероживильної системи офсетної листової друкарської машини в значній мірі залежить від функціонування повітряно-вакуумної системи, яка призначена для точної та надійної подачі аркушів у друкарську секцію.

Автоматизація керування процесами повітряно-вакуумної системи самонакладу повинна забезпечувати надійність і безперервність подачі аркушів та запобігати появі подвійних аркушів.

Однією 3 основних задач управління повітряно-вакуумною системою є цифрове визначення основних параметрів, залежно від значення яких визначаються сигнали для стабілізації системи подачі аркушів: тиск вакууму в присосах, тиск повітря в роздувах та вологість паперу на стапельному столі.

У зв'язку з цим актуальним $€$ дослідження засобів цифрового визначення параметрів повітряно-вакуумної системи подачі аркушів в офсетних листових друкарських машинах.

\section{Аналіз попередніх} досліджень

Сучасний стан та проблеми застосування повітряно-вакуумних систем подачі аркушів у папероживильних системах відображені у роботах $[1,2]$. Розглянуто варіанти апаратного забезпечення повітряновакуумної системи самонакладу, визначені основні її недоліки та обмеження в експлуатації. 
На основі математичного моделювання визначаються тенденції процесів автоматизованого управління повітряно-вакуумною системою листових друкарських машин [3, 4]. Основні параметри системи (тиск для забезпечення вакууму в присосах, тиск повітря при роздувах листів та вологість паперу), значення яких мають достатній вплив на продуктивність папероживильної системи друкарської машини та, які необхідно стабілізувати у процесі роботи самонакладу. Дослідження параметрів системи показали, що протягом робочого циклу компресору зазначені параметри мають динамічний характер.

Аналіз сучасних папероживильних систем показав, що малодослідженим залишається питання цифрового визначення та регулювання параметрів процесу подачі паперу на транспортуючий стіл, що потребує сучасних підходів для цифрового управління повітряно-вакуумною системою самонакладу та забезпечення аналізу експериментальних параметрів вимірювання на основі статистичних методів обробки результатів вимірювань у реальному масштабі часу.

\section{Мета роботи}

Метою дослідження $€$ аналіз та розробка автоматизованої цифрової системи визначення параметрів повітряно-вакуумної системи із застосуванням цифрових програмно-апаратних засобів статистичної обробки результатів вимірювань та управління в офсетних листових друкарських машинах.

\section{Результати проведених досліджень}

Для контролю основних технологічних параметрів повітряно-вакуумної системи була розроблена структурна схема системи цифрового вимірювання та управління визначеними параметрами (рис. 1).

Вимірювання цифрових параметрів системи базується на перетворенні аналогової інформації від датчика тиску вакууму в присосах, датчика тиску повітря в роздувах та датчика вологості паперу у стопі на стапельному столі. Сигнали з кожного датчика подаються на відповідні входи аналого-цифрового перетворювача (АЦП) для цифрової обробки.

Для забезпечення достовірності отриманих значень технологічних параметрів повітряно-вакуумної системи застосовується статистичний метод обробки вимірів [4] для визначення цифрових параметрів системи, тобто проводяться виміри вихідних сигналів на основі АЦП1,2,3 (16 вимірів по кожному АЦП) та їх аналіз за критерієм Пірсона. За допомогою програмного забезпечення проводяться визначення та аналіз параметрів, який базується на математичній моделі на основі рівнянь (1)-(2) [5].
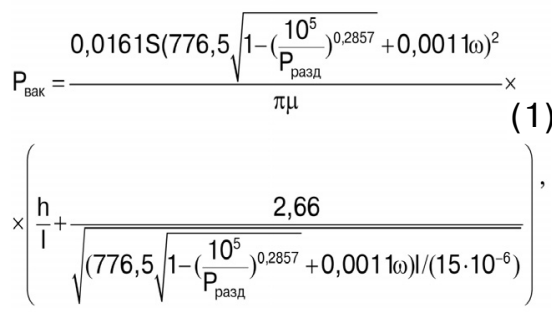
$P_{\text {разд }}=\left(\begin{array}{l}\left.98035 \cdot \operatorname{arscin}\left(\frac{\mathrm{h}}{\mathrm{l}}\right) \mathrm{S} \cdot\right)^{3,5} \times \\ \cdot \cos \left[\arcsin \left(\frac{\mathrm{h}}{\mathrm{l}}\right)\right]\end{array}\right)^{-3,5} \times$
$\times\left(\begin{array}{l}98035 \cdot \operatorname{arscin}\left(\frac{\mathrm{h}}{\mathrm{I}}\right) \mathrm{S} \cdot \\ \cdot \cos \left[\arcsin \left(\frac{\mathrm{h}}{\mathrm{l}}\right)\right]-\left(\rho_{0}+\rho_{\Delta}\right)\end{array}\right)^{-3,5} \times 10^{5}$

де $\mathrm{P}_{\text {вак }}$ - значення вакууму в присосах; $\mathrm{P}_{\text {разд }}$ - тиск повітря в роздувах; S - площа паперу; $\omega$ - кутова швидкість присосів; h - відстань між присосами та стапелем; I - довжина паперу; $\rho_{0}$ - початкова вологість паперу; $\rho_{\Delta}-$ змінна вологість.

Програмне керування виконавчими пристроями здійснюється за допомогою цифрово-аналогового перетворювачів $\left(Ц А \Pi_{1,2}\right)$ та частотного перетворювача сигнали надходять до компресорів повітряної та вакуумної підсистем для стабілізації параметрів.

Експериментальні дослідження цифрового вимірювання технологічних параметрів повітряно-вакуумної системи подачі аркушів проводились у виробничих умовах (друкарська

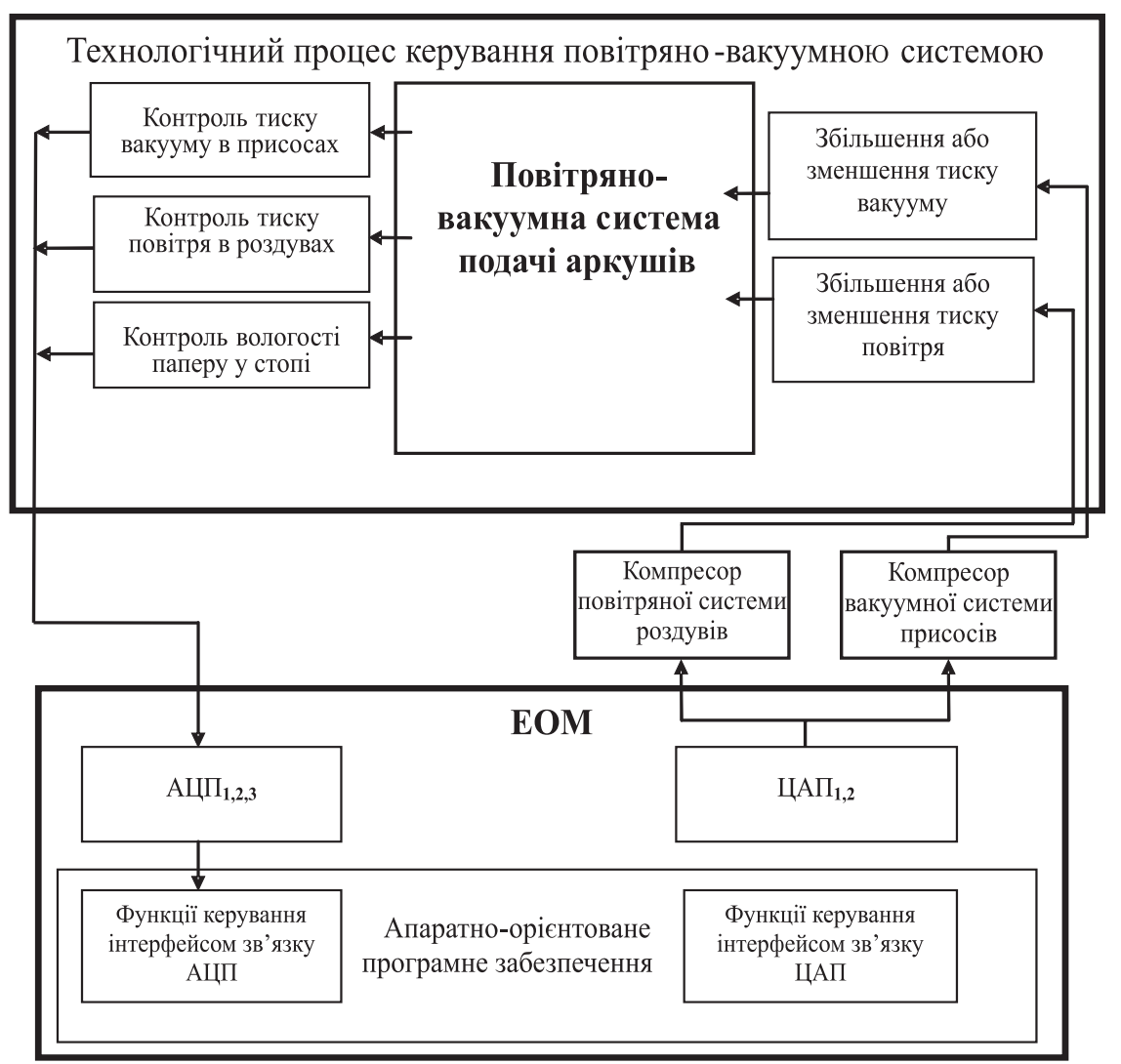

Рис. 1. Структурна схема системи цифрового вимірювання та управління технологічними параметрами повітряно-вакуумної системи подачі аркушів 
машина Heidelberg-Speedmaster XL 105, папір формату $340 \times 480$ мм, масою 55 г/м²) на основі програмно-апаратних засобів автоматичного цифрового визначення параметрів, 3 використанням проблемноорієнтованого програмного забезпечення для обробки отриманих результатів.

Вихідні вимірювання та результати корегування тиску повітря в роздувах повітряновакуумної системи приведені в табл.

Експериментальна обробка масивів вихідних даних виконувалась на основі програми на проблемно-орієнтованій мові $[6,7]$, яка забезпечує статистичний аналіз за критерієм $\chi^{2}$ та корегування аномальних значень вимірювань на основі критерія Шовене.

Для обробки експериментальних вимірів, які не розподілені у відповідності з законом Гауса, використовуються методи їх оцінки для визначення аномальності, що дозволяє виявити елементи масиву вимірів відмінних від решти за відповідним критерієм. Алгоритмічне забезпечення [8] статистичного оцінювання та визначення тиску повітря в роздувах представлено на рис. 2.

Порівняльна оцінка вихідних та скорегованих вимірювань зображена на рис. 3.

Рис. 3 свідчить, що в результаті статистичної обробки отримано корекцію аномальних значень № 4 і № 14 масиву вимірювань. За першу ітерацію корегування вимірювання № 14 змінилось зі значення 0,45 на 0,52, за другу ітерацію вимірювання № 15 - 3 0,63 на 0,53.

Це дозволяє отримати найкращу оцінку вимірювання значення тиску повітря в роздувах повітряно-вакуумної системи самонакладу офсетної листової машини, 053 bar.

Вихідні вимірювання та результати коригування тиску повітря в роздувах повітряно-вакуумої системи

\begin{tabular}{|c|c|c|}
\hline \multirow{2}{*}{ № виміру } & \multicolumn{2}{|c|}{ Тиск повітря в роздувах, bаr } \\
\cline { 2 - 3 } & $\begin{array}{c}\text { Вихідні } \\
\text { вимірювання }\end{array}$ & $\begin{array}{c}\text { Вихідні і скореговані } \\
\text { вимірювання }\end{array}$ \\
\hline 1 & 0,500 & 0,500 \\
\hline 2 & 0,510 & 0,510 \\
\hline 3 & 0,540 & 0,540 \\
\hline 4 & $\mathbf{0 , 4 5}$ & $\mathbf{0 , 5 2}$ \\
\hline 5 & 0,52 & 0,52 \\
\hline 6 & 0,53 & 0,53 \\
\hline 7 & 0,54 & 0,54 \\
\hline 8 & 0,55 & 0,55 \\
\hline 9 & 0,53 & 0,53 \\
\hline 10 & 0,54 & 0,54 \\
\hline 11 & 0,55 & 0,55 \\
\hline 12 & 0,54 & 0,54 \\
\hline 13 & 0,53 & 0,53 \\
\hline 14 & $\mathbf{0 , 6 3}$ & $\mathbf{0 , 5 3}$ \\
\hline 15 & 0,54 & 0,54 \\
\hline 16 & 0,54 & 0,54 \\
\hline
\end{tabular}




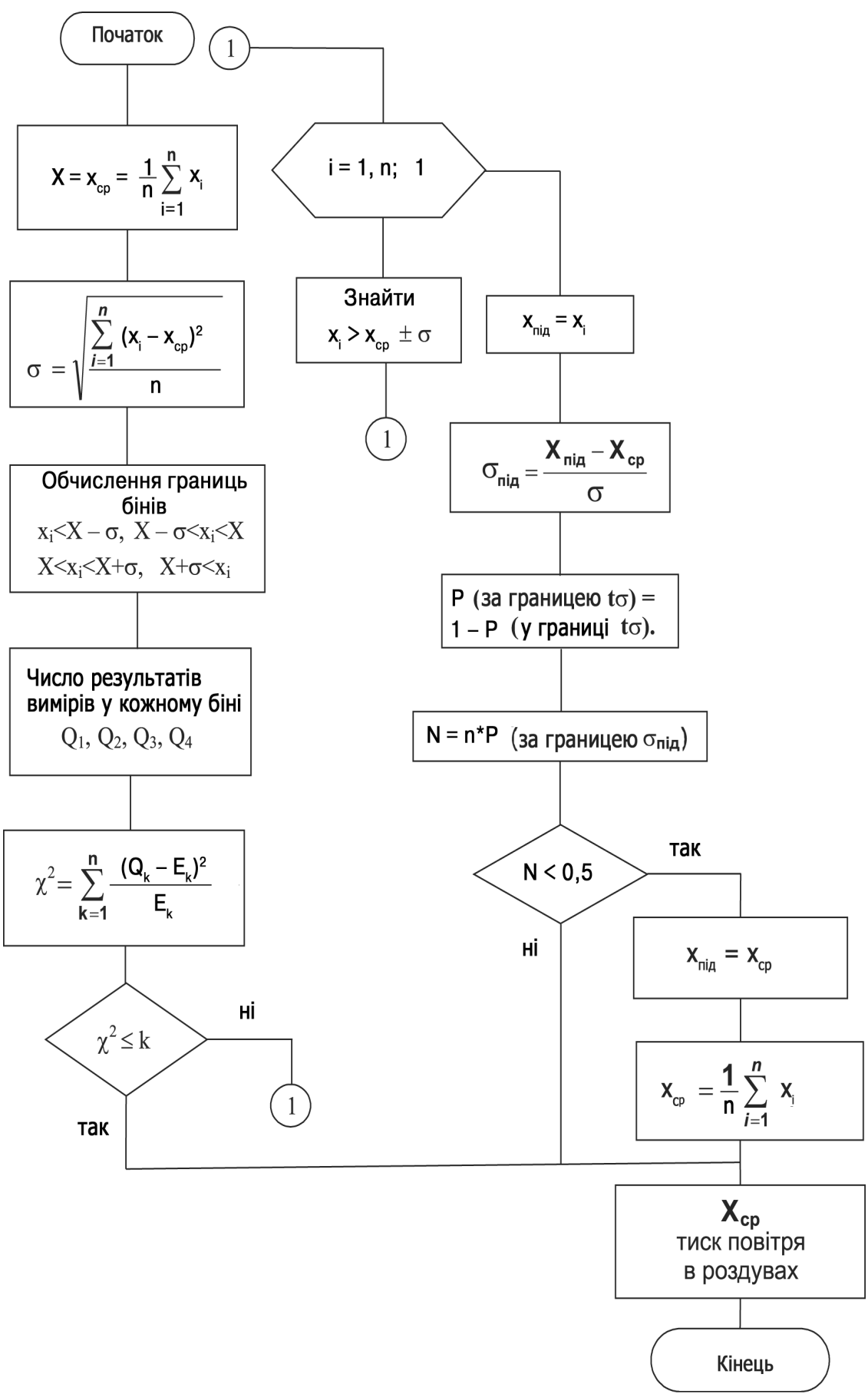

Рис. 2. Алгоритмічне забезпечення статистичного оцінювання та визначення тиску повітря в роздувах повітряно-вакуумної системи 


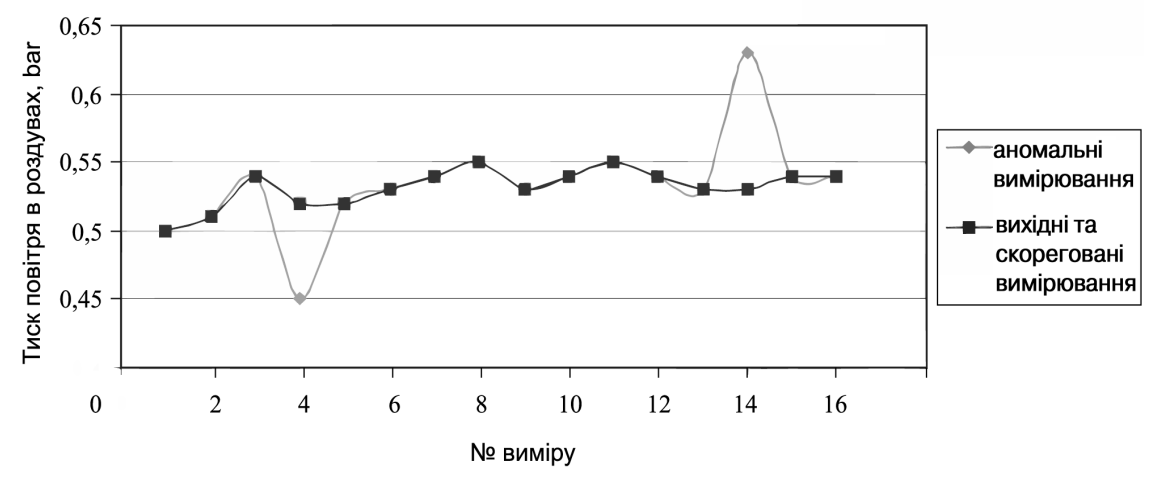

Рис. 3. Графік вихідних та скорегованих вимірювань

\section{Висновки}

1. Автоматизація процесів цифрового визначення технологічних параметрів повітряно-вакуумної системи подачі аркушів із застосуванням статистичної обробки результатів вимірювання для формування керуючих сигналів забезпечує стабільність подачі аркушів на транспортуючий стіл.

Об'єднання процесів вимірювання та статистичної обробки надає можливість автоматизації папероживильної системи та забезпечує його об'єктивність.

1. Колонтай И. И. Варианты реализации программно-аппаратного обеспечения адаптивного управления вакуумно-воздушной системой самонаклада / И. И. Колонтай // Труды БГтУ. Сер. IX. Издат. дело и полиграфия. - 2011. - С. 124-127. 2. Штоляков В. И. Автоматическое управление листовой офсетной печатной машиной и её сервис / В. И. Штоляков // Новости полиграфии. - 2005. - № 15. - С. 9-10. 3. Колонтай И. И. Моделирование процесса управления подачей бумаги в самонакладе / И. И. Колонтай, В. С. Юденков // Труды БГТУ. Сер. ІХ. Издат. дело и полиграфия. 2004. - Вып. XII. - С. 58-60. 4. Морфлюк В. Ф. Автоматизація процесів статистичного визначення натягу полотна паперу у рулонних друкарських машинах / В. Ф. Морфлюк // Технологія і техніка друкарства : зб. наук. пр. - К. : ВПІ НТУУ «КПІ». — 2008. - № 1. - С. 89-96. 5. Колонтай И. И. Математическая модель адаптивной системы управления самонакладом печатной машины / И. И. Колонтай // Труды БГТУ. Сер. IX. Издат. дело и полиграфия. - 2006. - Вып. XIV. - С. 73-77. 6. Морфлюк В. Ф. Статистичне оцінювання та визначення натягу паперового полотнища у рулонних друкарських машин / В. Ф. Морфлюк // Друкарство. - 2003. - № 3. С. 62-64. 7. Морфлюк В. Ф. Проблемно-орієнтовані засоби керування технологічним процесом друку / В. Ф. Морфлюк // Комп'ютерні технології друкарства : зб. наук. пр. - Л. : УАД. - 2002. - № 8. - С. 62-66. 8. Морфлюк В. Ф. Цифрове визначення та стабілізація параметрів технологічних процесів у рулонних друкарських машинах / В. Ф. Морфлюк. - К. : ВПЦ «Київ. політехніка», 2008. - 164 с.

1. Kolontaj I. I. Varianty realizacii programmno-apparatnogo obespechenija adaptivnogo upravlenija vakuumno-vozdushnoj sistemoj samonaklada / I. I. Kolontaj // Trudy BGTU. Ser. IX. Izdat. delo i poligrafija. - 2011. - 
S. 124-127. 2. Shtoljakov V. I. Avtomaticheskoe upravlenie listovoj ofsetnoj pechatnoj mashinoj i ejo servis / V. I. Shtoljakov // Novosti poligrafii. - 2005. № 15. - S. 9-10. 3. Kolontaj I. I. Modelirovanie processa upravlenija podachej bumagi v samonaklade / I. I. Kolontaj, V. S. Judenkov // Trudy BGTU. Ser. IX. Izdat. delo i poligrafija. - 2004. - Vyp. XII. - S. 58-60. 4. Morfliuk V. F. Avtomatyzatsiia protsesiv statystychnoho vyznachennia natiahu polotna paperu u rulonnykh drukarskykh mashynakh / V. F. Morfliuk // Tekhnolohiia i tekhnika drukarstva : zb. nauk. pr. - K. : VPI NTUU «KPI». - 2008. — № 1. - S. 89-96. 5. Kolontaj I. I. Matematicheskaja model' adaptivnoj sistemy upravlenija samonakladom pechatnoj mashiny / I. I. Kolontaj // Trudy BGTU. Ser. IX. Izdat. delo i poligrafija. - 2006. - Vyp. XIV. - S. 73-77. 6. Morfliuk V. F. Statystychne otsiniuvannia ta vyznachennia natiahu paperovoho polotnyshcha u rulonnykh drukarskykh mashyn / V. F. Morfliuk // Drukarstvo. - 2003. - № 3. - S. 62-64. 7. Morfliuk V. F. Problemno-oriientovani zasoby keruvannia tekhnolohichnym protsesom druku / V. F. Morfliuk // Komp'iuterni tekhnolohii drukarstva : zb. nauk. pr. - L. : UAD. - 2002. — № 8. - S. 62-66. 8. Morfliuk V. F. Tsyfrove vyznachennia ta stabilizatsiia parametriv tekhnolohichnykh protsesiv u rulonnykh drukarskykh mashynakh / V. F. Morfliuk. - K. : VPTs «Kyiv. politekhnika», 2008. -164 s.

$$
\begin{array}{r}
\text { Рецензент - Ю. О. Шостачук, к.т.н., } \\
\text { доцент, НТУУ «КП।» }
\end{array}
$$

Надійшла до редакції 20.12.12 